\title{
O DESPERTAR DAS MÁQUINAS NA CULTURA AUDIOVISUAL: CINEMA, TECNOLOGIA E IMAGINÁRIOS SOBRE O FUTURO
}

The awakening of machines in audiovisual culture: cinema, technology and imaginaries about the future

El despertar de las máquinas en la cultura audiovisual: cinema, tecnología e imaginarios sobre el futuro

Willian Fernandes Araújo Doutor em Comunicação e Informação pela Universidade Federal do Rio Grande do Sul willianfaraujo@gmail.com

\section{Entrevista com Antoni Roig Telo}

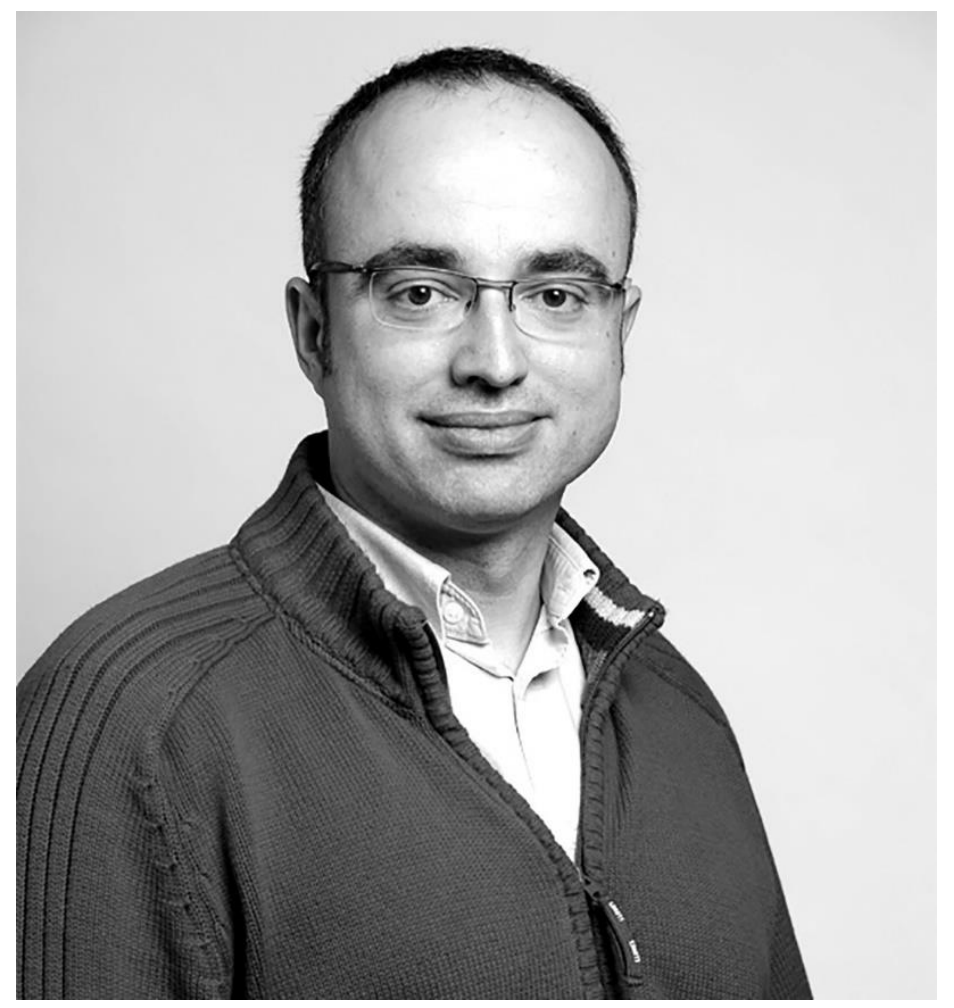

Como tecnologia e como discurso social, o cinema tem contribuído para o imaginário popular com uma pluralidade de reflexões sobre nossas relações com a técnica. Seja em cenários futurísticos onde podemos habitar outros planetas ou em distopias do presente nas quais a 
inteligência artificial passa a ter intencionalidade, as narrativas audiovisuais têm produzido discursos sobre seus contextos de produção e circulação, refletindo assim nossos mais intrínsecos medos, desejos e interesses. Nesse sentido, o cinema é "uma tecnologia que se situou em um lugar privilegiado para oferecer-nos relatos que falam sobre a tecnologia em uma perspectiva ampla e inclusiva" (ROIG, 2017, p. 10). Essa é a tradução livre de uma frase da introdução do livro $E l$ Despertar De Las Maquinas - 50 Peliculas Clave Sobre Tecnologia, do autor espanhol Antoni Roig Telo. Nessa publicação, Roig apresenta 50 filmes que ao longo da história do cinema proporcionaram visões sobre tecnologia como eixo de suas narrativas. A abordagem trazida pelo livro não se limita às tecnologias digitais, proporcionando ao leitor ou leitora uma seleção refinada, plural e abrangente. Desse modo, o autor foi capaz aprofundar sua análise também para os contextos que cercam essas narrativas, trazendo consigo interessantes pensamentos sobre os medos e aspirações de cada época.

Em entrevista realizada em junho de 2017, Antoni Roig discorre sobre a relação entre tecnologia e cinema, os imaginários sobre o futuro, assim como sobre as perspectivas contemporâneas da cultura audiovisual. Ele é doutor em Sociedade da Informação pela Universitat Oberta de Catalunya (UOC), onde atualmente também é professor de Estudos de Informação e Comunicação e diretor do programa de comunicação audiovisual.

\section{Há muito tempo narrativas audiovisuais têm tomado tecnologias e suas circunstâncias como importante eixo temático. Em sua opinião, como essas abordagens, muitas vezes falando de um futuro ou um passado distante, refletem questões e debates das sociedades e tempos nos quais essas narrativas são produzidas?}

Em cada momento histórico, a sociedade e a tecnologia, em um sentido amplo, têm mantido uma relação ambivalente e muitas vezes contraditória. Por um lado, as novas tecnologias do momento atuam como um símbolo do 'novo', como um valor social. Essa evidência do progresso é entendida como um tipo de relato muito específico que nos leva a um mundo utópico aperfeiçoada pela tecnologia. Tudo isso tem uma derivação cultural, social e, claramente, econômica. A sensação de evolução tecnológica nos permite pensar que avançamos para algum lado, que não podemos estar parados, que devemos 'adaptarmos', 'saltar' no trem do progresso. E, por isso, estar em dia com o que é mais atualizado. 
Por outro lado, as novas tecnologias nos permitem projetar um futuro, alimentar um imaginário de futuro. O cinema de ficção científica, ou com elementos de ciência-ficção, é um cenário no qual explicamos possíveis imaginários do futuro. Mas também podemos encontrá-los em filmes sobre o passado e sobre o presente, que abordem o conflito relacionado com a mudança entre o que foi e o que chegou a ser, ou entre o que somos e o que podemos chegar a ser. Nessas projeções é possível entrever reflexos de nossos desejos e medos. Algumas dessas emoções são quase ancestrais, outras são mais conjunturais e outras são mais simples. Podemos expressar o medo de perder o trabalho por culpa do surgimento de novas máquinas, ou de desumanizarmos, de sermos controlados pelos poderosos que dominam a tecnologia, ou de perder o controle de nossas invenções e sermos exterminados ou escravizados por elas ou por nossa própria incompetência... E também emoções relacionadas com a capacidade do homem de superar a si mesmo através da tecnologia, poder superar novos objetivos, romper limites, chegar a novas fronteiras, adquirir maior liberdade e autonomia tanto pessoal como social. Estou certo que o leitor encontrará facilmente exemplos na cultura popular, no cinema, na televisão e em quadrinhos. É certo que as distopias atuais têm muito a ver com um tipo de tecnologia específico, as que estão relacionadas com computadores, dispositivos e redes informáticas, mas estão voltadas a questões mais materiais e algumas vezes se voltando a questões profundamente filosóficas, como a imortalidade, a consciência, a moralidade e os limites do humano e do artificial.

\section{No seu último livro El Despertar De Las Maquinas - 50 Peliculas Clave Sobre Tecnologia, você fez uma seleção minuciosa de filmes importantes que refletem diferentes perspectivas sobre tecnologia. Qual o conceito de tecnologia considerado nessa seleção?}

Reunir 50 filmes representativos das relações entre cinema e tecnologia foi um trabalho terrivelmente difícil. Em pouco tempo preparei uma lista de quase 300! Em primeiro lugar tive que aceitar que não poderia identificar realmente 'os 50'. Para tornar essa uma missão mais acessível, me propus toda uma série de restrições: em primeiro lugar, que apareceriam de décadas e países distintos. Com isso tentei minimizar, ainda que levemente, o predomínio do cinema norteamericano e contemporâneo, mesmo que a maioria dos títulos selecionados ainda sejam de origem norte-americana e mais ou menos contemporâneos. 
Queria dar ao livro uma aproximação histórica que permitisse ao leitor, em diversas ocasiões, voltar a temas semelhantes, como a expansão espacial, mas de épocas diferentes. O espaço de Méliès ${ }^{1}$ (Viagem à Lua ${ }^{2}$ ), de Lang ${ }^{3}$ (A Mulher na Lua ${ }^{4}$ ), de Kubrick ${ }^{5}$ (2001 - Uma Odisseia no Espaço ${ }^{6}$ ) ou o de Scott $^{7}$ (Perdido em Marte ${ }^{8}$ ), são alguns exemplos do livro, nos mostram o caminho entre o mais desaforadamente fantasioso até à reivindicação do regresso e à ilusão coletiva com a conquista do espaço em um momento que o espaço já havia perdido parte do seu mistério. E tudo isso em pouco mais de 100 anos! Uma das coisas que mais gostei ao escrever o livro foi estabelecer relações entre os diferentes filmes, formando ou não parte dos 50 escolhidos, assim como com séries de televisão e outras formas culturais como a literatura e os quadrinhos. Por um lado, busquei ultrapassar a identificação entre tecnologia e as tecnologias informáticas ou eletrônicas. Na verdade, até mesmo das tecnologias relacionadas com máquinas. Desse modo, utilizei uma aproximação ampla da tecnologia, vinculada aos relatos nos quais são desenhadas ou apresentadas como técnicas viáveis, ferramentas, dispositivos ou sistemas que respondem a uma necessidade ou desejo da humanidade. Por outro lado, me propus a estudar objetos e tecnologias não apenas como naves espaciais, computadores, mundos virtuais, videogames ou robôs, mas também automóveis, aviões, a televisão ou, por que não, uma máquina de gelo, uma fábrica têxtil, um edifício gigantesco, o fogo, um arco e uma flecha ou mesmo o cinema, se essas histórias nos ajudam a entender a relação entre as pessoas e a tecnologia? Tentei abordar mais do que apenas os objetos, mas também o que os rodeia: o contexto social que abraça, recusa, ignora ou se apropria de uma invenção tecnológica, da mítica figura do inventor, ou até o pânico moral. Pois os relatos sobre a tecnologia são frequentemente relatos sobre a mudança, a demonstração de onde podemos ir, junto com a advertência sobre o que deveríamos evitar a todo custo, sobre aquilo que precisamos permanecer cautelosos.

\footnotetext{
${ }^{1}$ Georges Méliès

${ }^{2}$ Título original: Le Voyage dans la lune

${ }^{3}$ Fritz Lang

${ }^{4}$ Título original: Frau im Mond

${ }^{5}$ Stanley Kubrick

${ }^{6}$ Título original: 2001: A Space Odyssey

${ }^{7}$ Ridley Scott

${ }^{8}$ Título original: The Martian
} 
3. $\mathrm{O}$ audiovisual tem evoluído significativamente nos últimos 40 anos, principalmente pela introdução da computação gráfica. Como a evolução tecnológica do modo de fazer vídeo tem influído nas novas narrativas sobre tecnologia?

No momento, me passam pela cabeça ao menos três elementos-chave: em primeiro lugar, permitiu fazer verossímil o que anteriormente era impossível de mostrar em uma tela, gerando novos espaços de fascinação e de atração para o público, algumas vezes hiper-realistas e em outras ocasiões profundamente irreais ou fantásticas. Em segundo lugar, alteraram profundamente nossa maneira de expressão em audiovisual, introduzindo ingredientes como a tridimensionalidade, a interatividade e a ubiquidade. E, em terceiro, convertendo-se no eixo de muitas de suas histórias, que nos transmitem uma maior sensação de vertigem.

4. No panorama das séries de televisão nas últimas décadas é possível apontar uma gama de novas narrativas nas quais a tecnologia é o eixo temático principal, seja como um futuro distante ou um prosseguimento do presente. Você acredita que estamos em um momento comparável à década de 1980, dada a grande produção de discursos sobre a tecnologia?

Completamente. As séries de televisão são uma das principais fontes atuais de projeção do nosso imaginário sobre a tecnologia e, em alguns casos, pelo seu caráter seriado, mas também por suas rotinas de produção mais periódicas, estabelecendo laços mais diretos com a realidade. Junto a séries claramente sobre ficção científica como X-Files, Battlestar Galactica, Fringe, The 100 ou The Expanse, encontramos outras que, como Black Mirror, nos apresentam mundos de aparência mais realista, parecendo situar-se, como disse Alex Garland (roteirista e diretor de ExMachina), a "10 minutos do presente; é o caso de Westworld, Orphan Black, Humans (ou a sua versão original Real Humans), sem esquecer de tecno-thrillers como Person of Interest ou Mr. Robot, onde a vigilância e a fragilidade de um sistema sócio-político baseado na tecnologia é exposto de forma evidente.

Nesse sentido, há um caso que me encantou, de uma série aparentemente menor, mas muito importante ao situar-se no coração do universo massivo da Marvel: na quarta temporada de Marvel's Agents of Shield foram combinadas duas linhas de argumento muito presentes na ficção contemporânea e que exemplificaram esta dualidade de medo e fascinação pela tecnologia. Por um lado, a presença de uma inteligência artificial (A.i.D.A., nome humano que corresponde a Artificial Intelligent Digital Assistant), que se vê superior ao seu criador e que aspira ser um ser humano 
completo e, por outro lado, um mundo virtual completamente realista no qual se pode tornar real aquilo que uma pessoa desenhou e nunca pode levar a cabo no mundo real.

5. No Brasil, se escuta muito a seguinte frase: "Isso é muito Black Mirror". Como você observa as apropriações que os espectadores fazem de metáforas tecnológicas para refletir sobre seus cotidianos?

Parece-me muito interessante. Na Espanha tenho observado comentários parecidos, principalmente quando a terceira temporada estreou no Netflix, provavelmente ampliando sua base de fãs. Black Mirror tem essa virtude de permitir ao espectador identificar-se com o que está vendo, com suas motivações... Não nos custa lembrar de alguém que conhecemos que seja obcecado por gravar tudo, por despejar toda sua vida nas redes sociais, por curtir tudo e a todo custo para melhorar sua reputação pessoal ou pessoas capazes de deixar-se levar pela 'telerealidade', sem questionar aspectos éticos. Talvez esses sejamos nós mesmos. O elemento de antecipação simplesmente nos leva as situações ao extremo, mas seguimos identificando o que vemos como algo próximo, como um espelho deformado de nosso dia a dia. E rapidamente integramos isso em nossas conversas, pois é cotidiano e as vezes é surpreendente. Algo parecido acontece com $\mathrm{Mr}$. Robot, por exemplo, sem sair do tema televisão.

\section{Na série de televisão Westworld, a moralidade e autonomia da inteligência artificial são temas centrais em discussão. Quais lhe parecem ser os temas mais relevantes sobre o futuro da tecnologia nas narrativas audiovisuais do cotidiano?}

Westworld é um exemplo brilhante sobre a posição moral dos seres humanos em relação ao nosso mundo, uma posição que cremos 'possuir', convertendo ao 'outro' em coisas, inclusive quando esse outro apresenta o mesmo aspecto que nós. Essa é a grande diferença em relação à história original de Michael Crichton, na qual não se chegava a outorgar a condição realmente 'humana' aos robôs.

Temas relevantes? Bem, provavelmente já mencionei alguns deles ao longo da nossa conversa. Por exemplo, o grande tema da imortalidade é refletido na possibilidade de transferir nossa consciência por meios tecnológicos, seja a um corpo ou a um mundo virtual. A inteligência artificial coloca em questões os limites entre o ser humano e o ser artificial, assim como sobre o controle de nossas invenções; um caso particular é o ressurgimento da noção de ciborgue, do 
humano 'melhorado' por meios tecnológicos ou biotecnológicos. Já faz muitos anos que surgiu com força o medo da nossa inação para lidar com os recursos do Planeta ou deter sua superexploração: é outra expressão do medo de perder o controle sobre nosso entorno por conta de nossas próprias ações e progresso incontrolado (inclusive isso pode relacionar-se com a popularidade do subgênero do terror sobre zumbis).

A tensão entre liberdade e segurança através da tecnologia é um dos principais impulsos mantidos nas sociedades tecnologicamente avançadas: do ceticismo em relação aos governos ou às corporações privadas até nossa aceitação em reduzir a privacidade é um debate social que se reflete frequentemente nas narrativas audiovisuais. Outro tema interessante é o retorno à materialidade. Quer dizer, a maior atenção a 'tecnologias tangíveis' e físicas, nas quais o ser humano recupera protagonismo para além do 'virtual'. É possível observar isso em diversos filmes que reivindicam a figura do 'inventor' (O jogo da imitação ${ }^{9}$, Vidas ao Vento ${ }^{10}$, Steve Jobs, Operação Big Hero ${ }^{11}$, Ex_Machina, Tomorrowland - Um Lugar Onde Nada é Impossível) ou a ação das pessoas para chegar com sua intuição e força de vontade onde as máquinas não podem chegar (pensemos, por exemplo, em Gravidade ${ }^{12}$ ou Perdido em Marte ${ }^{13}$ ).

\section{Autores como Ian Bogost ${ }^{14}$ (2015) têm criticado as abordagens que chamam de} 'devocionais' sobre a tecnologia, principalmente pelos meios de comunicação e pelos pesquisadores, garantindo um status de divindade à tecnologia. Você considera que as narrativas audiovisuais contribuem para complexificação do debate público sobre os impactos do desenvolvimento tecnológico?

Bogost tem razão sobre existir uma tendência em apresentar avanços tecnológicos como algo natural. Não consideramos o que está por trás das 'recomendações' que são feitas em nosso consumo de mídias sociais e aceitamos essas interações como autêntica 'personalização', neutras, quase mágicas. O mesmo vale para as tecnologias de 'segurança': há alguns anos ocorriam intensos debates sobre a privacidade nos espaços públicos. Hoje em dia chegamos a aceitar a presença de

\footnotetext{
${ }^{9}$ Título original: The Imitation Game

${ }^{10}$ Título original: Kaze Tachinu

${ }^{11}$ Título original: Big Hero 6

12 Título original: Gravity

13 Título original: The Martian

${ }^{14}$ Disponível em: <https://www.theatlantic.com/technology/archive/2015/01/the-cathedral-ofcomputation/384300/>.
} 
câmeras em todas as partes e se possa invadir nossa privacidade através de nossos dispositivos e redes. Ainda que o audiovisual tenha contribuído em muitas ocasiões para espetacularizar a tecnologia e motivar nossas fascinações pelo progresso, minha experiência ao escrever o livro tem servido também para observar como essas narrativas servem como uma chamada à reação, usando os conflitos para estimular uma certa 'atitude vigilante' diante do estado do mundo. É simplesmente como as narrativas funcionam, movendo-se entre nossos sonhos e nossos medos mais profundos: se a partir daí quisermos, podemos tirar contribuições para questionar as visões lineares e naturalizadas do progresso, que parecem querer levar-nos inevitavelmente a algum lugar, sem que se espere que possamos refletir sobre onde queremos ir e qual o motivo disso.

\section{Original recebido em: 07 de agosto de 2017}

Aceito para publicação em: 07 de novembro de 2017

Willian Fernandes Araújo Doutor em Comunicação e Informação pela Universidade Federal do Rio Grande do Sul

Esta obra está licenciada sob uma Licença Creative Commons. 